\title{
Liquidity and hedging effectiveness under futures mispricing: international evidence
}

\author{
A. Andani*, J.A. Lafuente ${ }^{* *}$, A. Novales ${ }^{* * *}$
}

December 2008

\begin{abstract}
We analyze the hedging effectiveness of positions that replicate stock indexes using corresponding futures contracts through the application of a dynamic, stochastic hedging strategy proposed by Lafuente and Novales (2003). Conclusive gains do not emerge in any of the markets analyzed over the period considered, relative to the use of a constant unit hedge ratio. These findings are consistent with the trend observed in the IBEX 35 futures market study of Lafuente and Novales (2003). Our empirical evidence suggests that, contrary to what happens in less liquid markets, the discrepancy between theoretical and quoted prices in index futures contracts in fully developed markets does not represent a noise factor that can be successfully exploited for hedging.
\end{abstract}

Key words: futures mispricing, hedging effectiveness,

JEL classification: C22;F31;F47.

Financial support from Spanish Ministry of Education through grant SEJ20061454 is gratefully acknowledged.

* Corporate Finance Planning Director. Martinsa-Fadesa

** Corresponding author: Departamento de Finanzas y Contabilidad, Facultad de Ciencias Jurídicas y Económicas. Universitat Jaume I, 12071 Castellón (Spain). Email: lafuen@cofin.uji.es.

*** Departamento de Economía Cuantitativa. Facultad de Ciencias Económicas y Empresariales. Universidad Complutense de Madrid, 28223 Somosaguas (Spain). 


\section{INTRODUCTION}

Financial futures are frequently used in hedging operations, in which the determination of the hedge ratio is the main issue. Several theoretical approaches have been proposed in the literature to design an optimal hedge with futures contracts (see Chen et al., 2003, for an excellent review that considers minimum variance, meanvariance, expected utility, mean extended-Gini coefficient, and semivariance approaches). The usual approach takes into account not only the dynamic nature of market risk, but also the fact that the key idea of hedging is to combine spot and futures trading to form a portfolio with negligible fluctuations in its market value. Under that view, the decision is to choose the number of futures contracts that minimizes the conditional variance of the return on the hedged portfolio. The resulting optimal hedge ratio is then obtained as the ratio between the conditional covariance of spot and futures returns and the conditional variance of futures returns. These conditional moments have usually been estimated from a particular specification of the GARCH family of models (see, for example, Lee and Yoder, 2007, Ku et al., 2007, Choudhry, 2003 and 2004, Park and Switzer, 1995 among many others).

This study reviews the use of futures contracts on a specific stock market index as hedging instrument for a portfolio that replicates the market index. After showing that the empirical evidence is consistent with the absence of a common $\mathrm{ARCH}$ feature between the returns from spot and futures markets, we adopt the theoretical ratio proposed by Lafuente and Novales (2003), which is consistent with the existence of a noise specific to the future market in addition to a noise common to spot and futures market returns. A bivariate model with heteroskedastic disturbances is used to represent the dynamics of returns in both markets in order to estimate the minimum variance hedge ratio.

After estimating with data for 1997-2005, empirical evidence obtained from outof-sample simulations over 2006 for the Nikkei 225, S\&P500, FTSE-100, DAX and IBEX 35 futures markets shows no systematic improvement in hedging effectiveness relative to using a constant unit hedging ratio, contrary to results in Lafuente and 
Novales (2003) for the IBEX 35 index for 1993-1996. We explore whether this result is consistent with the trend pointed out by Lafuente and Novales (2003) in their stochastic optimal hedge ratio towards one over the 1993-1996 period, with a decreasing gain in hedging efficiency relative to a unitary ratio, which the authors justified on the basis of increased maturity of a still underdeveloped and illiquid market. Our goal is to analyze whether that trend continued after 1996, as the Spanish market increased liquidity, as well as to examine the robustness of our empirical results by examining similar evidence in fully developed markets in the US, Japan and Germany.

If confirmed, such a finding would suggest that in mature index futures markets with high trading volume, the time-varying noise that characterizes basis risk cannot be exploited to improve upon the hedging efficiency provided by a systematic unit ratio. Our results are fully in line with Roll et al. (2007), who present empirical evidence suggesting that liquidity enhances the efficiency of the futures-cash pricing system.

The rest of the paper is organized as follows. Section 2 describes the data used in the analysis and the results of testing for the presence of a common ARCH feature in the spot and futures markets returns. Section 3 presents the model used to determine the optimal hedge ratio and describes the estimation of the relevant conditional moments. Section 4 presents the empirical evidence on the evolution of conditional moments over the analyzed period. A simulation of hedging trading is performed to test the potential implementation of the model, and section 5 summarizes and makes concluding remarks.

\section{STATISTICAL CHARACTERISTICS OF RETURNS}

We used daily closing data for the IBEX35, FT100, NIKKEI225, DAX and SP500 indexes. We select the trading day for the rollover of contracts according to the evolution of the depth of futures market. Figure 1 shows the average relative trading volume between the nearest to maturity contract and the next to maturity contract. With the exception of the S\&P 500 futures market, the other derivatives markets considered exhibit greater trading volume for the next to maturity contract all the way to expiration. In the American market, volumes traded reverse around five days before expiration. 
The time period we consider, January 1997 to December 2006, is interesting because of the occurrence of several events: a) the financial crisis of 1998 that significantly affected the United States financial system; b) the technology bubble burst in 2000; c) the subsequent deep generalized recession that spread across markets and lasted until the beginning of 2003, and d) a subsequent period of systematic market stability, with the exception of isolated crises due to geo-political tensions and inflationary fears. The latter part of this period was characterized by abundant liquidity in capital markets, with low interest rates.

Table 1 presents the main statistics for the return series, computed as the first differences of the logs of closing prices between successive trading days. The sample mean daily return is negligible, as expected from a systematically long and short trading strategy on consecutive trading days. Likewise, as is usually the case with daily time series, stock return distributions show excess kurtosis and some skewness, characteristics generally associated with conditional heteroskedasticity. To assess the existence of ARCH effects in stock returns, we perform Engle's Lagrange multiplier test. Empirical values of the test, not reported in the paper, systematically reject the null, pointing to the convenience of using some parameterization for second order moments of stock market returns in the family of GARCH models.

In order to empirically justify the use of our proposed model, which assumes the existence of a noise common to spot and futures returns, together with a noise specific to the yield of the derivative instrument, we follow the approach of Engle and Kozicki (1993) to test the null hypothesis that there is a linear combination of the returns from the two markets which is homoskedastic, i.e., that the ARCH feature is common to both return series. The empirical values of the test statistic are presented in Table 2, systematically leading to rejection of the hypothesis of a common ARCH feature. This pattern is consistent with the proposed theoretical model. 


\section{OPTIMAL DYNAMIC HEDGING}

\subsection{The optimal hedge ratio}

In accordance with the empirical evidence above, we follow Lafuente and Novales (2003) consider that the hedging problem can be specified:

$$
\begin{aligned}
& \underset{\left\{h_{t}\right\}}{\operatorname{Min}_{i}} \operatorname{Var}_{t}\left(b_{t} \frac{d S_{t}}{S_{t} d t}-h_{t} \frac{d F_{t, T}}{F_{t, T} d t}\right) \\
& \text { s.t. } \\
& d S_{t}=\mu_{S, t} S_{t} d t+\sigma_{S, t} S_{t} d z_{1, t} \\
& d F_{t, T}=\mu_{f, t} F_{t, T} d t+\sigma_{S, t} F_{t, T} d z_{1, t}+\sigma_{N, t} F_{t, T} d z_{2, t}
\end{aligned}
$$

where $b_{t}$ denotes the spot position we want to hedge, and $h_{t}$ is the hedging futures position, while $S_{\mathrm{t}}$ and $F_{t}$ represent spot and futures market prices, respectively. We denote the correlation between the two Brownian processes: $\rho_{12, t}=\operatorname{Corr}\left(d z_{1 t}, d z_{2 t}\right)$. $\sigma_{S i t}$ denotes the size of the common noise shared by the two markets. The discrepancy between the price quoted in the futures market and the theoretical price according to the cost-of-carry valuation model arises from a basis risk of size $\sigma_{N, t}$, that we specifically attribute to the futures market. As shown in Lafuente and Novales (2003), the theoretical expression for the minimum variance (optimal) hedge ratio solving the problem above is:

$$
\frac{h_{t}^{*}}{b_{t}}=\frac{\sigma_{s, t}^{2}+\rho_{12, t} \sigma_{s, t} \sigma_{N, t}}{\sigma_{s, t}^{2}+\sigma_{N, t}^{2}+2 \rho_{12, t} \sigma_{s, t} \sigma_{N, t}}=\frac{1+\rho_{12, t} \delta_{t}}{1+\delta_{t}^{2}+2 \rho_{12, t} \delta_{t}}
$$

where $\delta_{t}=\frac{\sigma_{N, t}}{\sigma_{S, t}}$ represents the relative importance of the specific noise as compared to the common noise. Under the proposed model, the optimal hedge ratio remains below one provided that spot and futures market returns do not share a single common noise. The optimal ratio is positive (implying a short futures position) when both disturbances are positively correlated. In contrast, if the correlation between the two noises was negative, the optimal hedge ratio could lie either above or below 1.0. 


\subsection{Estimating time-varying variances for the theoretical noises}

Given the conclusive empirical evidence in the literature on the existence of a cointegration relationship between the logarithms of spot market and futures market prices, our specification of the conditional mean for both series of returns incorporates an error correction term. Lien (1996) shows that disregarding the cointegrating relationship could lead to a smaller than optimal futures position and a relatively poor hedging performance. There is also abundant empirical evidence [see Lien and Yang (2006), among many others] supporting the hypothesis that the cointegration vector is $(1,-1)$ which, in turn, implies that the empirical basis is stationary. Estimated cointegration vectors for the pair: $[\log ($ futures price) $\log ($ spot price)] by Johansen's procedure, after normalizing the first entry to unity are: S\&P 500: [1.000, -1.005], Nikkei 225: [1.000, -1.015], FTSE100: [1.000, -1.006], DAX: [1.000, -1,001], Ibex35: [1, -0,999]. In all cases, the null hypothesis of the cointegration vector being $[1.000,-1.000]$ is not rejected at conventional significant levels. Hence, we define the error correction term as the "spread" between the logarithm of the spot price and the future price.

To capture the correlations between the return innovations and estimate the conditional variance-covariance matrix of spot and futures markets returns, we use the bivariate dynamic conditional correlation (DCC) GARCH model proposed in Engle (2002). Monte Carlo experiments reveal not only that the bivariate version of the DDCMV-GARCH model provides a very good approximation to a variety of time-varying correlation processes, but also that this model often compares favorably with the simple multivariate GARCH. The (DCC) GARCH specification combines the flexibility of univariate GARCH models with a parsimonious parametric specification for the conditional correlation. Furthermore, bearing in mind the objectives of the present study, Ku et al (2007) compare the DCC-GARCH model proposed in Engle (2002) with the constant correlation specification, to find evidence of greater hedging effectiveness from the model with time-varying correlation.

Hence, we represent the dynamics of spot and futures markets returns, $r_{s, t}$ and $r_{f, t}$, through the error correction model:

$$
\left(\begin{array}{l}
r_{s, t} \\
r_{f, t}
\end{array}\right)=\sum_{i=1}^{n}\left(\begin{array}{ll}
\alpha(i)_{11} & \alpha(i)_{12} \\
\alpha(i)_{21} & \alpha(i)_{22}
\end{array}\right)\left(\begin{array}{l}
r_{s, t-i} \\
r_{f, t-i}
\end{array}\right)+\left(\begin{array}{l}
\gamma_{s} \\
\gamma_{f}
\end{array}\right)\left(\ln S_{t-1}-\ln F_{t-1}\right)+\left(\begin{array}{l}
\varepsilon_{s, t} \\
\varepsilon_{f, t}
\end{array}\right)
$$


with $\left(\varepsilon_{s, t} \varepsilon_{f, t}\right)^{\prime} / \Omega_{t-1} \sim N\left(0, \Sigma_{t}\right)$, where $\Omega_{t-1}$ is the information set available at time $t-1$ and $\Sigma_{t}$ is the conditional variance-covariance matrix of market return innovations ${ }^{1}$.

We represent the time evolution of the elements in the conditional variancecovariance matrix by a $\operatorname{GARCH}(p, q)$ specification with possible asymmetric effects:

$$
\begin{aligned}
& \left(\begin{array}{l}
\sigma_{s, t}^{2} \\
\sigma_{f, t}^{2}
\end{array}\right)=\left(\begin{array}{l}
\omega_{s} \\
\omega_{f}
\end{array}\right)+\sum_{i=1}^{p}\left(\begin{array}{ll}
A(i)_{11} & A(i)_{12} \\
A(i)_{21} & A(i)_{22}
\end{array}\right)\left(\begin{array}{l}
\varepsilon_{s, t-i}^{2} \\
\varepsilon_{f, t-i}^{2}
\end{array}\right)+\sum_{j=1}^{q}\left(\begin{array}{ll}
B(j)_{11} & B(j)_{12} \\
B(j)_{21} & B(j)_{22}
\end{array}\right)\left(\begin{array}{l}
\sigma_{s, t-1}^{2} \\
\sigma_{f, t-1}^{2}
\end{array}\right) \\
& +\left(\begin{array}{ll}
D_{11} & D_{12} \\
D_{21} & D_{22}
\end{array}\right)\left(\begin{array}{l}
\varepsilon_{s, t-1}^{2} I_{s, t-1} \\
\varepsilon_{f, t-1}^{2} I_{f, t-1}
\end{array}\right), \quad I_{k, t-1}=\left\{\begin{array}{l}
1, \text { si } \varepsilon_{k, t-1}<0, k=s, f \\
0, \text { si } \varepsilon_{k, t-1}<0, k=s, f
\end{array}\right\}
\end{aligned}
$$

With regard to the conditional correlation, the dynamics of the DCC model is:

$$
\rho_{s f, t}=\left(1-\kappa_{1}-\kappa_{2}\right) \bar{\rho}+\kappa_{1} \rho_{s f, t-1}+\kappa_{2} \Psi_{t-1}
$$

where:

$$
\Psi_{t-1}=\frac{\sum_{h=1}^{m} \eta_{s, t-h} \eta_{f, t-h}}{\sqrt{\left(\sum_{h=1}^{m} \eta_{s, t-h}^{2}\right)\left(\sum_{h=1}^{m} \eta_{f, t-h}^{2}\right)}}, \eta_{k, t}=\frac{\varepsilon_{k, t}}{\sigma_{k, t}}, k=s, f
$$

Once the conditional moments have been estimated, the conditional variance for futures market returns, as well as their conditional covariance and correlation with spot market returns can be recovered using the expressions in Lafuente and Novales (2003):

$$
\begin{aligned}
& \hat{\sigma}_{f, t}^{2}=\hat{\sigma}_{s, t}^{2}+\hat{\sigma}_{N, t}^{2}+2 \hat{\sigma}_{s, t} \hat{\sigma}_{N, t} \hat{\rho}_{12, t} \\
& \hat{\sigma}_{s f, t}=\hat{\sigma}_{s, t}^{2}+\hat{\sigma}_{s, t} \hat{\sigma}_{N, t} \hat{\rho}_{12, t} \\
& \hat{\rho}_{12, t}=\frac{\hat{\sigma}_{s f, t}-\sigma_{s, t}^{2}}{\hat{\sigma}_{s, t} \sqrt{\hat{\sigma}_{s, t}^{2}+\hat{\sigma}_{f, t}^{2}-2 \hat{\sigma}_{s f, t}}}
\end{aligned}
$$

\footnotetext{
${ }^{1}$ When the Normality assumption was rejected for the residuals, we estimated the model using a t-Student conditional distribution for the innovations when evaluating the log-likelihood function.
} 
where $\hat{\sigma}_{f, t}^{2}, \hat{\sigma}_{s, t}^{2}$ and $\hat{\sigma}_{s, f, t}$ denote the conditional variances of futures and spot market returns and their conditional covariance, as estimated from the DCC-GARCH model.

\section{EMPIRICAL EVIDENCE}

The sample information was divided into two sub-periods. The first period runs from January 1997 to December 2005, which was used for initial estimation and specification testing. The second sub-period, from January 2006 to December 2006, was left as an out-of-sample window to test the effectiveness of simulated hedging operations.

\subsection{The bivariate GARCH model}

Table 3 shows the parameters obtained in the estimation of the DCCGARCH model. In all cases, we sought for the most parsimonious specification possible $^{2}$. In the case of the S\&P 500 and FTSE-100, a $t$-Student conditional distribution was considered, while the Normal distribution was used for IBEX 35, DAX and Nikkei225. In general, the estimates show significant coefficients for ARCH and GARCH effects, suggesting volatility clustering in both market returns. Similarly, the parameters that represent the cross effects in mean and variance also reveal significant cross-market interactions. The speed of adjustment to short-run price deviations from their long-run equilibrium is also significant, thus evidencing that the markets are arbitraged in such a way that the empirical basis has a restricted evolution over time. Finally, the presence of significant asymmetric effects should be noted for the SP500 as well as the Nikkei225. Figures 2a, 2b and 2c (see Appendix 2) show the evolution over time of the relative importance of the noise specific to the futures market, as compared to the common noise, $\hat{\sigma}_{N, t} / \hat{\sigma}_{s, t}$, in each of the stock markets considered.

\footnotetext{
${ }^{2}$ To assess the ability of the estimated model to capture the main statistical characteristics of market returns, a battery of standard specification tests was employed, including the Ljung-Box Q-statistics on the standardized residual and their squared values. All series of residuals were found to be free of serial correlation at the $5 \%$ significance level.
} 


\subsection{Hedging simulations}

Having estimated the model for the period 1997-2005, we incorporated data for the out-of-sample 2005-2006 period in 10-day windows. This is a compromise between maintaining a constant hedge ratio and changing the hedge too often, which would imply unbearable transaction costs. The model was re-estimated every 10 days, obtaining at each point a hedge ratio, before incorporating additional data on a 10-day period for a new estimation. Once the entire series of hedge ratios had been obtained for 2006, we implemented two different hedging strategies by applying to each 10-day trading window (the time interval $[t+1, t+10]$ ), either the hedge ratio estimated the last day in each rolling sample (at time $\mathrm{t}$ ) or the average hedge ratio computed over the last five trading days in each sample (from $t-4$ to $t$ ). Thus, the 250 market days in the year allowed for performing 25 10-day hedging operations with each strategy, except in the case of the NIKKEI, for which only 24 were carried out. ${ }^{3}$ The volatility of the series of returns on the portfolio hedged with the GARCH ratio was then obtained under each of these two hedging strategies, computing the reduction in volatility relative to the spot position. The volatility of the portfolio hedged with the unitary ratio was obtained similarly, and the implied reduction in volatility was also calculated. Finally, we compared the reduction in volatility obtained by application of each of the two strategies based on a GARCH ratio and the strategy based on imposing a constant unit ratio:

Hedging effectiveness $=100 \frac{\text { Volatility }(\text { hedged position })-\text { Volatility }(\text { Unhedged position })}{\text { Volatility }(\text { Unhedged position })}$

where volatility is measured by the standard deviation of returns over the period chosen for comparison.

We present results obtained throughout the out-of-sample period, as well as over each quarter. Tables 4 and 5 present the results of applying the two hedging strategies described in the previous paragraph. The results obtained do not exhibit a systematic advantage over the unit ratio, which suggests that the incorporation of transaction costs

\footnotetext{
${ }^{3}$ Due to the availability of a shorter number of market days.
} 
would make the application of a dynamic hedging strategy with the GARCH ratio even less interesting.

Finally, we now consider the gain or loss in terms of utility, taking into account the transaction costs from adjusting the position in the derivatives market. To this end, we consider a specification of the expected utility function: $E_{t} U(x)=E_{t}(x)-\gamma \sigma_{t}^{2}(x)$ [as in Kroner and Sultan (1993), Lee et al. (2006) and Kofman and McGlenchy (2005), among others], where $\gamma$ denotes the degree of risk aversion, with the level of risk being measured by the conditional variance of returns. Denoting transaction costs by $\tau$ and assuming a zero expected return, an investor would have an expected utility of $-\tau-\gamma \sigma_{t}^{2}\left(x^{* *}\right)$ if the hedge ratio is updated from $h_{t}^{*} / b_{t}$ to $h_{t}^{* *} / b_{t}$, as against an expected utility equal to $-\gamma \sigma_{t}^{2}\left(x^{*}\right)$ if the hedge ratio remains unchanged. Thus, an investor whose utility is given by the specification considered will adjust the hedging position if and only if:

$$
\tau-\gamma\left(\sigma_{s, t}^{2}-2 \sigma_{s f, t}\left(h_{t}^{* *} / b_{t}\right)+\sigma_{f, t}^{2}\left(h_{t}^{* *} / b_{t}\right)^{2}\right)>-\gamma\left(\sigma_{s, t}^{2}-2 \sigma_{s f, t}\left(h_{t}^{*} / b_{t}\right)+\sigma_{f, t}^{2}\left(h_{t}^{*} / b_{t}\right)^{2}\right)
$$

where $\left(h_{t}^{* *} / b_{t}\right)$ denotes the hedge ratio applied as the result of the last revision of the futures position.

To implement this strategy, we consider a risk aversion coefficient of 4 and average costs of $0.0011 \%{ }^{4}$, and the optimal ratio obtained in the last trading day in each rolling sample, $\mathrm{t}$, is applied to the following 10 trading days (from $t+1$ to $t+10$ ). Thus, over the out-of-sample period, we use the utility comparison rule every 10 trading days to decide on whether to maintain the same hedge ratio that was applied previously, or to change it to the variance-minimizing ratio calculated in the immediately preceding period. The results obtained for each market are presented in Table 6 in terms of aggregate utility for 2006 , as well as in terms of the utility gain relative to the non-

4 This corresponds to the MEFF Spanish commission of 1.3 Euros for the regular futures contract and the 2006 average value of the IBEX 35. As to the transaction costs associated to the bid-ask spread, we use the mean spread for the short-term index futures contracts on FTSE-100 $(1,4 £)$, as reported in Fahlenbrach and Sandas (2003). We applied the same commission to all indexes. Since the position does not change often, our results are robust to transaction costs inside a $(.0020 \%, .0060 \%)$ range. 
hedged market position. Managing the hedge ratio according to the utility comparison rule often provides the highest utility gain, but it is very similar to the one obtained under the constant unit ratio, as well as to the one emerging from applying the GARCH ratio from the previous period.

\section{CONCLUSIONS}

This paper analyzes the use of index futures as a hedging instrument for a portfolio that replicates the underlying asset for the futures contract. To this end, we have used the theoretical model proposed by Lafuente and Novales (2003), which includes a specific noise in the futures price in addition to the common noise that it is assumed to share with the spot market price, according to the cost-of-carry valuation model.

We have analyzed daily closing data on futures and spot markets for the NIKKEI225, SP500, FT100, DAX and IBEX35 indexes over the 1997-2005 period. The null hypothesis on the existence of a common ARCH feature [Engle and Kozicki (1993)] underlying the heteroskedastic behavior detected in spot and futures markets returns is rejected, validating the existence of a noise specific to the futures market, as included in our econometric model. We estimate an asymmetric bivariate errorcorrection model with a DCC-GARCH structure to represent the conditional mean, variance and covariance of future and spot market returns, and we simulate out-ofsample hedging strategies that apply a hedge ratio calculated from the estimated econometric specification.

The results show that GARCH dynamic strategies do not lead to a systematic improvement in hedging effectiveness, as compared to the improvement that would be obtained by applying a constant unit ratio.

These results are in sharp contrast with those obtained using intraday data for the period 1993-1996 by Lafuente and Novales (2003) for the Spanish market. One reason might be that the present study uses daily data, which implies a loss of information on price fluctuations that may bias upward the estimation of co-movement between spot and futures prices, moving optimal hedge ratios closer to 1 . 
But we believe that what is really central to explain the different results is the fact that the Spanish market was in 2006 a significantly more mature market, with a sufficiently high level of activity that would quickly correct any arbitrage opportunity. Indeed, our results are consistent with the trend detected in Lafuente and Novales (2003) about the optimal hedge ratio for the Spanish market gradually coming closer to 1 towards the end of the 1993-1996 sample period, thereby limiting the potential gain in hedging effectiveness obtained from the dynamic GARCH ratio. The similar conclusions we have reached for fully developed option markets in the US, Japan and Germany reinforce that interpretation.

The empirical evidence for the Spanish futures market is also consistent with the recent paper of McMillan and Quiroga (2008). These authors show that the equilibrium speed of adjustment between spot and futures market prices was reduced after the introduction of the mini-futures contract in the Spanish market in November 2001, the effect being particularly pronounced after the second year, when mini-futures contracts started being more heavily traded.

Even more significantly, the result that noisy deviations from the no-arbitrage relationship in mature market prices may be of no consequence for improving the efficiency of hedging a spot portfolio with futures contracts goes along the lines of Roll et al. (2007), who have shown evidence that liquidity enhances the efficiency of the futures-cash pricing system for the S\&P 500 stock index futures market. 


\section{REFERENCES}

Chen, S.-S., Lee, C.-F., Shrestha, K., 2003, Futures hedge ratios: a review, The Quarterly Review of Economics and Finance 43, 433-465.

Choudhry, T., 2004, The hedging effectiveness of constant and time-varying hedge ratios using three Pacific Basin stock futures, International Review of Economics \& Finance 4, 371-385.

Choudhry, T., 2003, Short-run deviations and optimal hedge ratio: evidence from stock futures, Journal of Multinational Financial Management 13, 171-192.

Engle, R.F., 2002, Dynamic conditional correlation: A simple class of multivariate generalized autoregressive conditional heteroskedasticity models, Journal of Business and Economic Statistics 20, 339-350.

Engle,R.F., Kozicki, S., 1993, Testing for common features, Journal of Business and Economic Statistics 11, 369-380.

Fahlenbrach, R., Sandas, P., 2003, Bid-Ask spreads and inventory risk: Evidence from the FTSE-100 Index Options Market. University of Pennsylvania.

Kofman P., McGlenchy, P., 2005, Structurally sound dynamic index futures hedging, Journal of Futures Markets 25, 1173-1202.

Koutmos, G., Tucker, M., 1996, Temporal relationships and dynamics interactions between spot and futures stock markets, Journal of Futures Markets 16, $55-69$.

Kroner, K.F, Sultan, J., 1993, Time-varying distributions and dynamic hedging with foreign currency futures, Journal of Financial and Quantitative Analysis 28, 535551.

$\mathrm{Ku}$, Y.H., Chen, H. Chen, K., 2007, On the application of the dynamic conditional correlation model in estimating optimal time-varying hedge ratios, Applied Economics Letters 7, 503-509.

Lafuente, J.A., Novales, A., 2003, Optimal hedging under departures from the cost-of-carry valuation: Evidence from the Spanish stock index futures market, Journal of Banking \& Finance 27, 1053-1078.

Lee, H., Yoder, J., Mittelhamner, J., McCluskey, R., 2006, A random coefficient autoregressive Markov switching model for dynamic futures hedging, Journal of Futures Markets 26, 103-129.

Lee, H., Yoder, J., 2007, Optimal hedging with a regime switching time-varying correlations GARCH model, Journal of Futures Markets 27, 495-516. 
Lien, D. (1996), The effect of the cointegration relationship on futures hedging: A note, The Journal of Futures Markets 16, 773-780.

Lien, D., Yang, Li., 2006, Spot-Futures Spread, Time-Varying Correlation, and hedging with Currency Futures, The Journal of Futures Markets 26, 1019-1038.

McMillan D.G., Quiroga R., 2008, Efficiency of the IBEX spot-futures basis: The impact of the mini-futures, Journal of Futures Markets 28, 398-415.

Park, T.H., Switzer, L.N., 1995, Bivariate Garch estimation of the optimal hedge ratios for stock index futures: A note, Journal of Futures Markets 15, 61-67.

Roll, R., Schwartz, E., A. Subrahmanyam, 2007, Liquidity and the law of one price: The case of the futures-cash basis, The Journal of Finance, 52, 5, 2201-2234. 


\section{Appendix 1. Tables}

Table 1 Descriptive statistics of stock market returns

\begin{tabular}{|c|c|c|c|c|c|c|c|c|c|c|}
\hline & \multicolumn{2}{|c|}{ NIKKEI225 } & \multicolumn{2}{|c|}{ SP500 } & \multicolumn{2}{|c|}{ FT100 } & \multicolumn{2}{|c|}{ DAX } & \multicolumn{2}{|c|}{ IBEX35 } \\
\hline & Spot & Futures & Spot & Futures & Spot & Futures & Spot & Futures & Spot & Futures \\
\hline Mean & -0.0001 & -0.0001 & 0.0003 & 0.0003 & 0.0002 & 0.0002 & 0.0003 & 0.0003 & 0.0004 & 0.0004 \\
\hline Standard Dev. & 0.0147 & 0.0152 & 0.0115 & 0.0119 & 0.0115 & 0.0120 & 0.0162 & 0.0161 & 0.0141 & 0.0148 \\
\hline Asymmetry & -0.0367 & -0.1741 & -0.0725 & $-0,1323$ & -0.1771 & -0.0867 & -0.2300 & -0.0040 & -0.1803 & -0.1734 \\
\hline Kurtosis & 1.7501 & 2.4852 & 3.0553 & 3,5657 & 2.5418 & 2.7153 & 2.6376 & 3.3604 & 2.4828 & 2.7844 \\
\hline
\end{tabular}

Table 2 Testing for common ARCH features

\begin{tabular}{lrrrrrrrrrr}
$K$ & 1 & 2 & 3 & 4 & 5 & 6 & 7 & 8 & 9 & 10 \\
\hline Min TR $^{2}$ & & & & & & & & & & \\
NIKKEI225 & 41.1 & 65.3 & 98.9 & 110.4 & 142.9 & 158.5 & 178.5 & 180.1 & 177.3 & 188.5 \\
SP500 & 70.5 & 113.6 & 160.0 & 169.9 & 187.1 & 189.8 & 207.4 & 223.3 & 224.5 & 238.8 \\
FT100 & 102.4 & 268.1 & 336.8 & 353.0 & 361.2 & 378.7 & 378.9 & 379.2 & 380.4 & 380.5 \\
DAX & 82.2 & 217.7 & 257.4 & 262.9 & 291.1 & 324.7 & 329.0 & 333.0 & 375.9 & 387.5 \\
IBEX & 83.1 & 153.3 & 197.6 & 228.2 & 229.5 & 281.6 & 324.7 & 348.4 & 350.1 & 370.2
\end{tabular}

Critical values

\begin{tabular}{lllllllllll}
$\alpha=0.05$ & 6.0 & 11.1 & 15.5 & 19.7 & 23.7 & 27.6 & 31.4 & 35.2 & 38.9 & 42.6 \\
$\alpha=0.01$ & 9.2 & 15.1 & 20.1 & 24.7 & 29.1 & 33.4 & 37.6 & 41.6 & 45.6 & 49.6 \\
\hline
\end{tabular}

Notes: The first panel shows the minimum $T^{*} \mathrm{R}^{2}$ in a set of regressions of $\left(\mathrm{r}_{\mathrm{s}, \mathrm{t}}-d \mathrm{r}_{\mathrm{f}, \mathrm{t}}\right)^{2}$ on $k$ lags of $\mathrm{r}_{\mathrm{s}, \mathrm{t}}^{2} \mathrm{r}_{\mathrm{f}, \mathrm{t}}^{2}$ and $\mathrm{r}_{\mathrm{s}, \mathrm{t}} \mathrm{r}_{\mathrm{f}, \mathrm{t}}$ over a grid of values for $d$, where $T$ denotes the sample size. The last two rows show critical values at the $\alpha-$ significance level. 
Table 3

Maximum Likelihood estimation of the parameters involved in the DCC-GARCH model NIKKEI225 SP500 FT100 DAX IBEX35

Spot mean equation

\begin{tabular}{|c|c|c|c|c|c|c|c|c|c|c|}
\hline$a_{11}$ & -0.037 & & -0.300 & $* *$ & -0.184 & $* *$ & -0.198 & $* *$ & -0.506 & $* *$ \\
\hline$a_{12}$ & 0.018 & & 0.286 & $* *$ & -0.224 & $* *$ & 0.230 & $* *$ & -0.290 & $* *$ \\
\hline $\mathrm{a}(2)_{11}$ & & & & & 0.200 & $* *$ & & & 0.515 & $* *$ \\
\hline $\mathrm{a}(2)_{12}$ & & & & & 0.203 & $* *$ & & & 0.275 & $* *$ \\
\hline $\mathrm{g}_{\mathrm{s}}$ & -0.406 & $* *$ & -0.085 & $* *$ & -0.070 & $*$ & -0.473 & $* *$ & -0.021 & \\
\hline \multicolumn{11}{|c|}{ Futures mean equation } \\
\hline $\mathrm{a}_{21}$ & 0.054 & & 0.097 & $* *$ & 0.296 & $* *$ & 0.139 & $* *$ & -0.219 & \\
\hline$a_{22}$ & -0.090 & & -0.110 & $* *$ & -0.003 & & -0.123 & $* *$ & -0.189 & \\
\hline $\mathrm{a}(2)_{21}$ & & & & & -0.274 & $* *$ & & & 0.230 & \\
\hline $\mathrm{a}(2)_{22}$ & & & & & -0.018 & & & & 0.166 & \\
\hline$g_{f}$ & 0.342 & $* *$ & -0.002 & & 0.020 & & -0.221 & $* *$ & 0.342 & $* *$ \\
\hline \multicolumn{11}{|c|}{ Spot Variance equation } \\
\hline $\mathrm{w}_{\mathrm{s}}$ & 0.000 & $* *$ & 0.000 & & 0.000 & & 0.000 & $* *$ & 0.000 & \\
\hline $\mathrm{A}_{11}$ & 0.024 & & -0.076 & $*$ & 0.176 & $* *$ & 0.004 & & -0.169 & $* *$ \\
\hline $\mathrm{A}_{12}$ & 0.038 & & 0.092 & $* *$ & -0.070 & & 0.123 & $* *$ & 0.207 & $* *$ \\
\hline $\mathrm{B}_{11}$ & 0.528 & & 1.013 & $* *$ & 0.633 & $* *$ & 0.877 & $* *$ & -1.602 & $*$ \\
\hline $\mathrm{B}_{12}$ & 0.351 & & -0.058 & & 0.247 & $* *$ & -0.005 & & 2.460 & $* *$ \\
\hline $\mathrm{D}_{11}$ & 0.079 & $* *$ & 0.049 & $* *$ & & & & & & \\
\hline $\mathrm{D}_{12}$ & 0.131 & $* *$ & 0.059 & $* *$ & & & & & & \\
\hline \multicolumn{11}{|c|}{ Futures Variance equation } \\
\hline $\mathrm{W}_{\mathrm{f}}$ & 0.000 & $*$ & 0.000 & & 0.000 & & 0.000 & $* *$ & 0.000 & \\
\hline $\mathrm{A}_{21}$ & 0.081 & & -0.056 & & 0.170 & $* *$ & 0.094 & $* *$ & 0.010 & \\
\hline $\mathrm{A}_{22}$ & -0.047 & & 0.066 & $*$ & -0.057 & & 0.033 & & 0.039 & \\
\hline $\mathrm{B}_{21}$ & 0.716 & $*$ & 0.031 & & -0.313 & $* *$ & -0.111 & $* *$ & -0.106 & \\
\hline $\mathrm{B}_{22}$ & 0.208 & & 0.924 & $* *$ & 1.184 & $* *$ & 0.978 & $* *$ & 1.049 & $* *$ \\
\hline $\mathrm{D}_{21}$ & 0.962 & $* *$ & -0.057 & $* *$ & & & & & & \\
\hline $\mathrm{D}_{22}$ & 0.361 & $* *$ & 0.037 & $* *$ & & & & & & \\
\hline \multicolumn{11}{|c|}{ Correlation dynamics } \\
\hline $\mathrm{k}_{1}$ & 0.037 & $*$ & 0.021 & & 0.143 & $* *$ & 0.112 & $* *$ & 0.009 & $*$ \\
\hline $\mathrm{k}_{2}$ & 0.959 & $* *$ & 0.970 & $* *$ & 0.800 & $* *$ & 0.870 & $* *$ & 0.990 & $* *$ \\
\hline
\end{tabular}

Note: In the case of the S\&P 500 and the FTSE-100, the conditional distribution is a t-Student. Degrees of freedom were estimated at 7.1 and 5.7 respectively. 
Table 4

Out-of-sample hedging effectiveness

\begin{tabular}{|c|c|c|c|c|}
\hline & \multirow{2}{*}{$\begin{array}{c}\text { GARCH } \\
\text { Hedge } \\
\text { Ratio } \\
\end{array}$} & \multicolumn{2}{|c|}{ Hedging effectiveness } & \multirow{2}{*}{$\begin{array}{l}\text { Difference (\%) } \\
\text { |GARCH|-|Unit. }\end{array}$} \\
\hline & & GARCH & Unitary & \\
\hline \multicolumn{5}{|l|}{ NIKKEI225 } \\
\hline January-March 2006 & 0.962 & $-81.34 \%$ & $-82.41 \%$ & $-1.07 \%$ \\
\hline April-June 2006 & 0.942 & $-81.90 \%$ & $-82.12 \%$ & $-0.22 \%$ \\
\hline July-September 2006 & 0.966 & $-76.45 \%$ & $-76.77 \%$ & $-0.32 \%$ \\
\hline September-December 2006 & 0.947 & $-75.49 \%$ & $-75.07 \%$ & $0.42 \%$ \\
\hline Average 2006 & 0.954 & $-79.78 \%$ & $-80.22 \%$ & $-0.44 \%$ \\
\hline \multicolumn{5}{|l|}{ SP500 } \\
\hline January-March 2006 & 0.975 & $-74.32 \%$ & $-74.73 \%$ & $-0.41 \%$ \\
\hline April-June 2006 & 0.967 & $-76.70 \%$ & $-77.36 \%$ & $-0.66 \%$ \\
\hline July-September 2006 & 0.976 & $-70.04 \%$ & $-70.53 \%$ & $-0.49 \%$ \\
\hline September-December 2006 & 1.001 & $-68.58 \%$ & $-68.89 \%$ & $-0.31 \%$ \\
\hline Average 2006 & 0.980 & $-73.37 \%$ & $-73.87 \%$ & $-0.50 \%$ \\
\hline \multicolumn{5}{|l|}{ FT100 } \\
\hline January-March 2006 & 1.002 & $-80.58 \%$ & $-80.54 \%$ & $0.03 \%$ \\
\hline April-June 2006 & 0.978 & $-88.91 \%$ & $-88.71 \%$ & $0.20 \%$ \\
\hline July-September 2006 & 0.990 & $-80.86 \%$ & $-80.86 \%$ & $0.00 \%$ \\
\hline September-December 2006 & 1.007 & $-79.63 \%$ & $-79.91 \%$ & $-0.28 \%$ \\
\hline Average 2006 & 0.995 & $-83.62 \%$ & $-83.59 \%$ & $0.03 \%$ \\
\hline \multicolumn{5}{|l|}{ DAX } \\
\hline January-March 2006 & 0.964 & $-83.01 \%$ & $-84.53 \%$ & $-1.52 \%$ \\
\hline April-June 2006 & 0.986 & $-77.66 \%$ & $-77.66 \%$ & $0.00 \%$ \\
\hline July-September 2006 & 0.981 & $-81.76 \%$ & $-82.60 \%$ & $-0.85 \%$ \\
\hline September-December 2006 & 0.955 & $-80.89 \%$ & $-81.02 \%$ & $-0.14 \%$ \\
\hline Average 2006 & 0.971 & $-80.06 \%$ & $-80.52 \%$ & $-0.45 \%$ \\
\hline \multicolumn{5}{|l|}{ IBEX35 } \\
\hline January-March 2006 & 0.945 & $-79.42 \%$ & $-79.90 \%$ & $-0.48 \%$ \\
\hline April-June 2006 & 0.951 & $-80.77 \%$ & $-80.86 \%$ & $-0.09 \%$ \\
\hline July-September 2006 & 0.946 & $-85.57 \%$ & $-87.29 \%$ & $-1.72 \%$ \\
\hline September-December 2006 & 0.966 & $-85.18 \%$ & $-85.76 \%$ & $-0.58 \%$ \\
\hline Average 2006 & 0.952 & $-82.43 \%$ & $-83.07 \%$ & $-0.63 \%$ \\
\hline
\end{tabular}

Note: The hedge ratio obtained for the last day in each rolling sample is applied to the following 10 trading days. 
Table 5

Out of-sample hedging effectiveness

\begin{tabular}{|c|c|c|c|c|}
\hline & \multirow{2}{*}{$\begin{array}{c}\text { GARCH } \\
\text { Hedge Ratio }\end{array}$} & \multicolumn{2}{|c|}{ Hedging effectiveness } & \multirow{2}{*}{$\begin{array}{r}\text { Difference (\%) } \\
\text { |GARCH|-|Unit. }\end{array}$} \\
\hline & & GARCH & Unitary & \\
\hline \multicolumn{5}{|l|}{ NIKKEI225 } \\
\hline January-March 2006 & 0.949 & $-80.81 \%$ & $-82.41 \%$ & $-1.60 \%$ \\
\hline April-June 2006 & 0.945 & $-82.12 \%$ & $-82.12 \%$ & $0.00 \%$ \\
\hline July-September 2006 & 0.949 & $-76.09 \%$ & $-76.77 \%$ & $-0.68 \%$ \\
\hline September-December 2006 & 0.942 & $-75.28 \%$ & $-75.07 \%$ & $0.20 \%$ \\
\hline Average 2006 & 0.946 & $-79.56 \%$ & $-80.22 \%$ & $-0.66 \%$ \\
\hline \multicolumn{5}{|l|}{ SP500 } \\
\hline January-March 2006 & 0.977 & $-74.32 \%$ & $-74.73 \%$ & $-0.40 \%$ \\
\hline April-June 2006 & 0.965 & $-76.55 \%$ & $-77.36 \%$ & $-0.81 \%$ \\
\hline July-September 2006 & 0.984 & $-70.14 \%$ & $-70.53 \%$ & $-0.39 \%$ \\
\hline September-December 2006 & 1.001 & $-68.69 \%$ & $-68.89 \%$ & $-0.21 \%$ \\
\hline Average 2006 & 0.982 & $-73.36 \%$ & $-73.87 \%$ & $-0.51 \%$ \\
\hline \multicolumn{5}{|l|}{ FT100 } \\
\hline January-March 2006 & 0.991 & $-80.34 \%$ & $-80.54 \%$ & $-0.20 \%$ \\
\hline April-June 2006 & 0.982 & $-88.74 \%$ & $-88.71 \%$ & $0.03 \%$ \\
\hline July-September 2006 & 0.991 & $-80.84 \%$ & $-80.86 \%$ & $-0.01 \%$ \\
\hline September-December 2006 & 1.005 & $-79.34 \%$ & $-79.91 \%$ & $-0.57 \%$ \\
\hline Average 2006 & 0.993 & $-83.49 \%$ & $-83.59 \%$ & $-0.10 \%$ \\
\hline \multicolumn{5}{|l|}{ DAX } \\
\hline January-March 2006 & 0.968 & $-83.33 \%$ & $-84.53 \%$ & $-1.20 \%$ \\
\hline April-June 2006 & 0.988 & $-77.65 \%$ & $-77.66 \%$ & $-0.01 \%$ \\
\hline July-September 2006 & 0.980 & $-82.06 \%$ & $-82.60 \%$ & $-0.55 \%$ \\
\hline September-December 2006 & 0.953 & $-80.89 \%$ & $-81.02 \%$ & $-0.13 \%$ \\
\hline Average 2006 & 0.973 & $-80.18 \%$ & $-80.52 \%$ & $-0.34 \%$ \\
\hline \multicolumn{5}{|l|}{ IBEX35 } \\
\hline January-March 2006 & 0.940 & $-79.36 \%$ & $-79.90 \%$ & $-0.55 \%$ \\
\hline April-June 2006 & 0.952 & $-80.80 \%$ & $-80.86 \%$ & $-0.06 \%$ \\
\hline July-September 2006 & 0.950 & $-85.72 \%$ & $-87.29 \%$ & $-1.57 \%$ \\
\hline September-December 2006 & 0.971 & $-85.31 \%$ & $-85.76 \%$ & $-0.45 \%$ \\
\hline Average 2006 & 0.954 & $-82.49 \%$ & $-83.07 \%$ & $-0.58 \%$ \\
\hline
\end{tabular}

Note: The average hedge ratio over the last five trading days in each rolling sample is applied to the following 10 trading days. 
Table 6

Utility gains under different hedging strategies

$\begin{array}{lllll}\text { NIKKEI225 } & \text { SP500 } & \text { FT100 } & \text { DAX } & \text { IBEX35 }\end{array}$

Aggregate utility

Spot position

$\begin{array}{lllll}-0.17320 & -0.04371 & -0.06721 & -0.10819 & -0.06527\end{array}$

Unitary hedge ratio

$\begin{array}{lllll}-0.00558 & -0.00261 & -0.00252 & -0.00976 & -0.00233\end{array}$

GARCH hedge ratio $(*)$

$\begin{array}{lllll}-0.00649 & -0.00381 & -0.00374 & -0.01095 & -0.00322\end{array}$

GARCH hedge ratio with decision criterion (**)

$\begin{array}{lllll}-0.00526 & -0.00256 & -0.00252 & -0.01091 & -0.00228\end{array}$

Utility gain on the spot position

Unitary hedge ratio

$\begin{array}{lllll}96.8 \% & 94.0 \% & 96.2 \% & 91.0 \% & 96.4 \%\end{array}$

GARCH hedge ratio $(*)$

$96.3 \% \quad 91.3 \% \quad 94.4 \% \quad 89.9 \% \quad 94.9 \%$

GARCH hedge ratio with decision criterion $(* *)$

$97.0 \% \quad 94.1 \% \quad 96.3 \% \quad 89.9 \% \quad 96.5 \%$

(*) The hedge ratio is changed every 10 days, applying the ratio from the last trading day in each rolling sample.

(**)The desirability of applying a new ratio was appraised every 10 days, the decision being made in accordance with the expected utility. 
Appendix 2. Figures

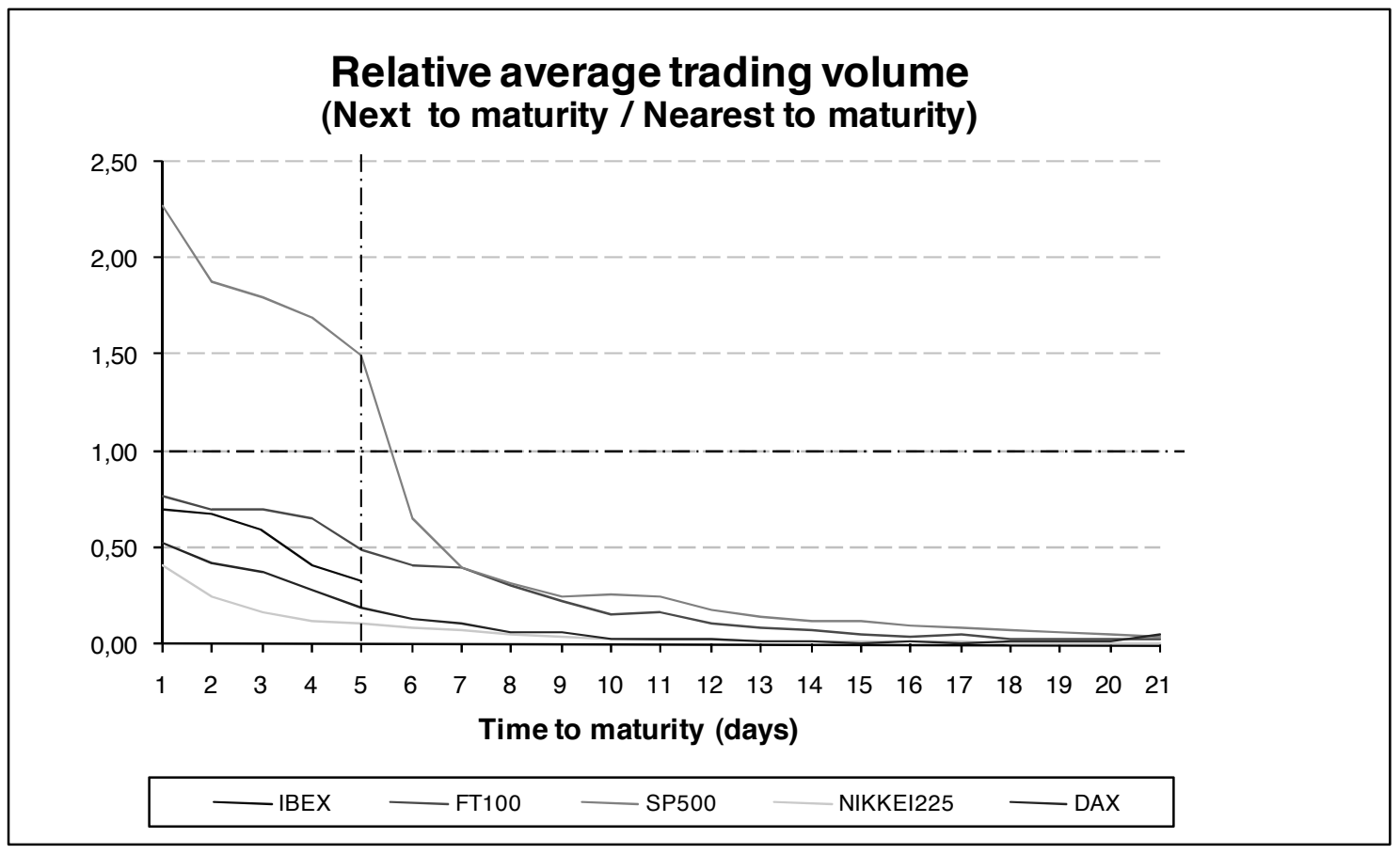

Figure 1. Relative volume traded in each stock market: number of next to maturity contracts traded over number of Nearest to maturity futures contracts traded, as a function of Time to maturity. 

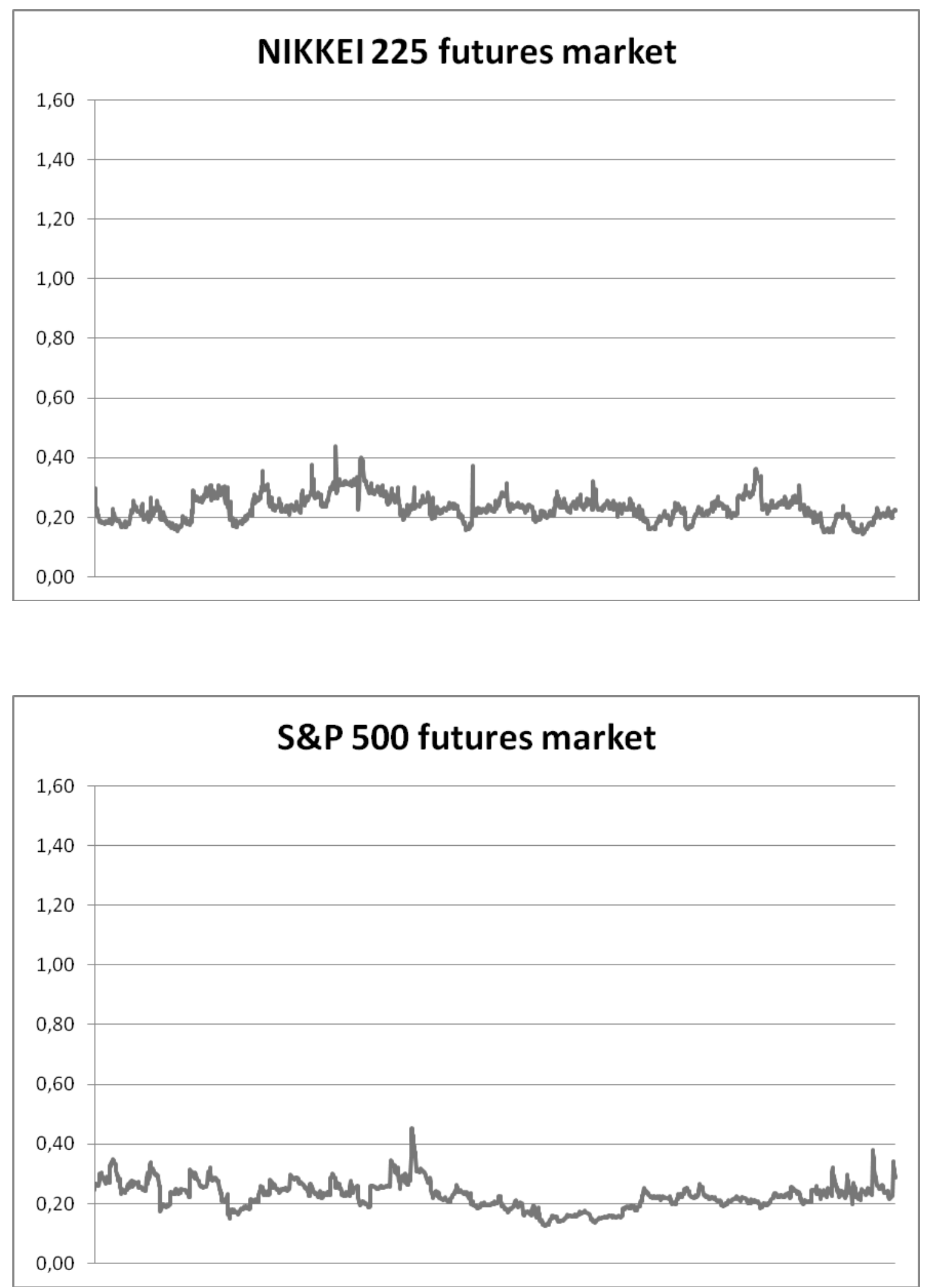

Figure 2a. Ratio of estimated variances for specific and common noise components: Nikkei225 and S\&P500. 

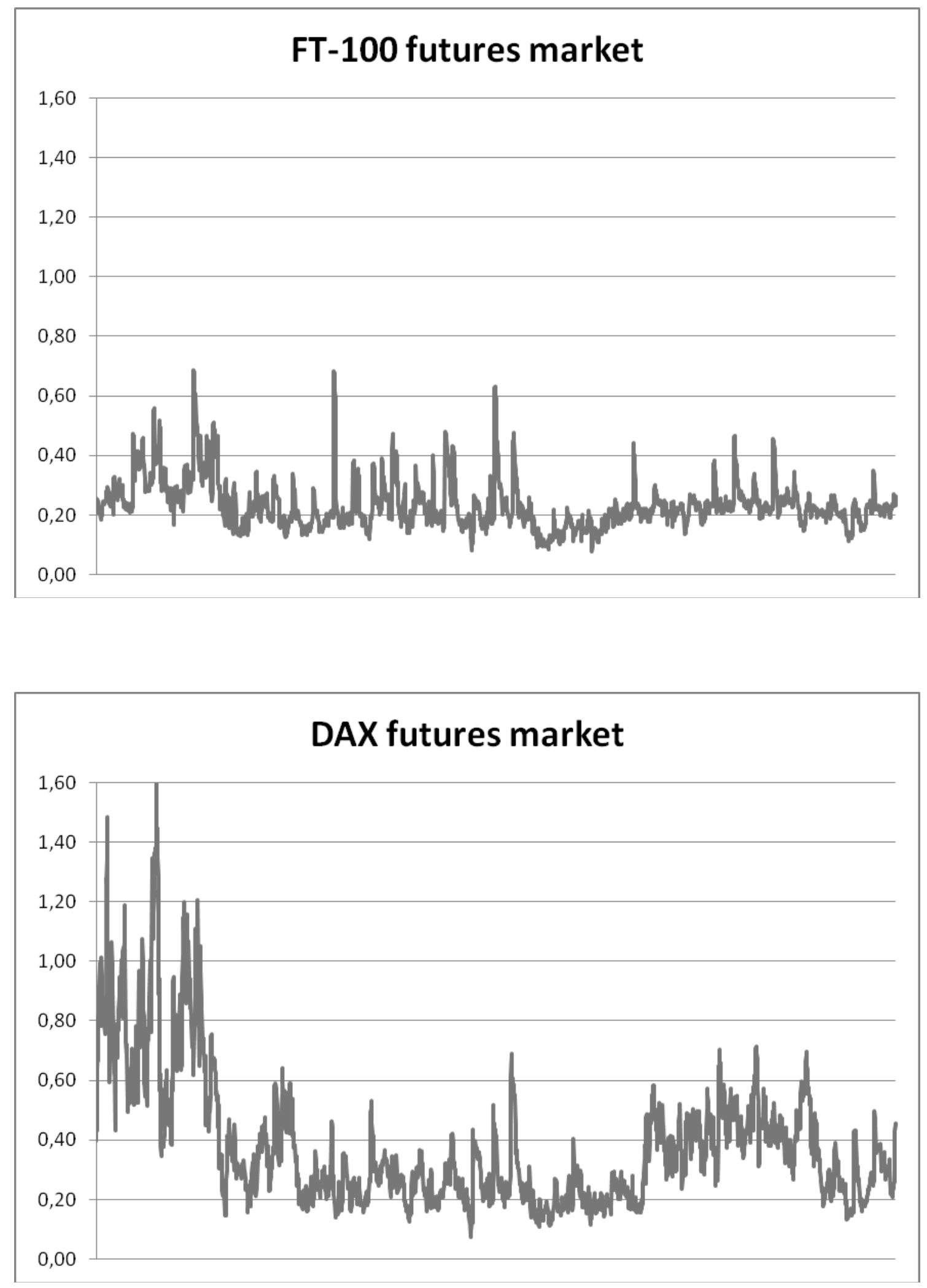

Figure 2b. Ratio of estimated variances for specific and common noise components: FT100 and DAX. 


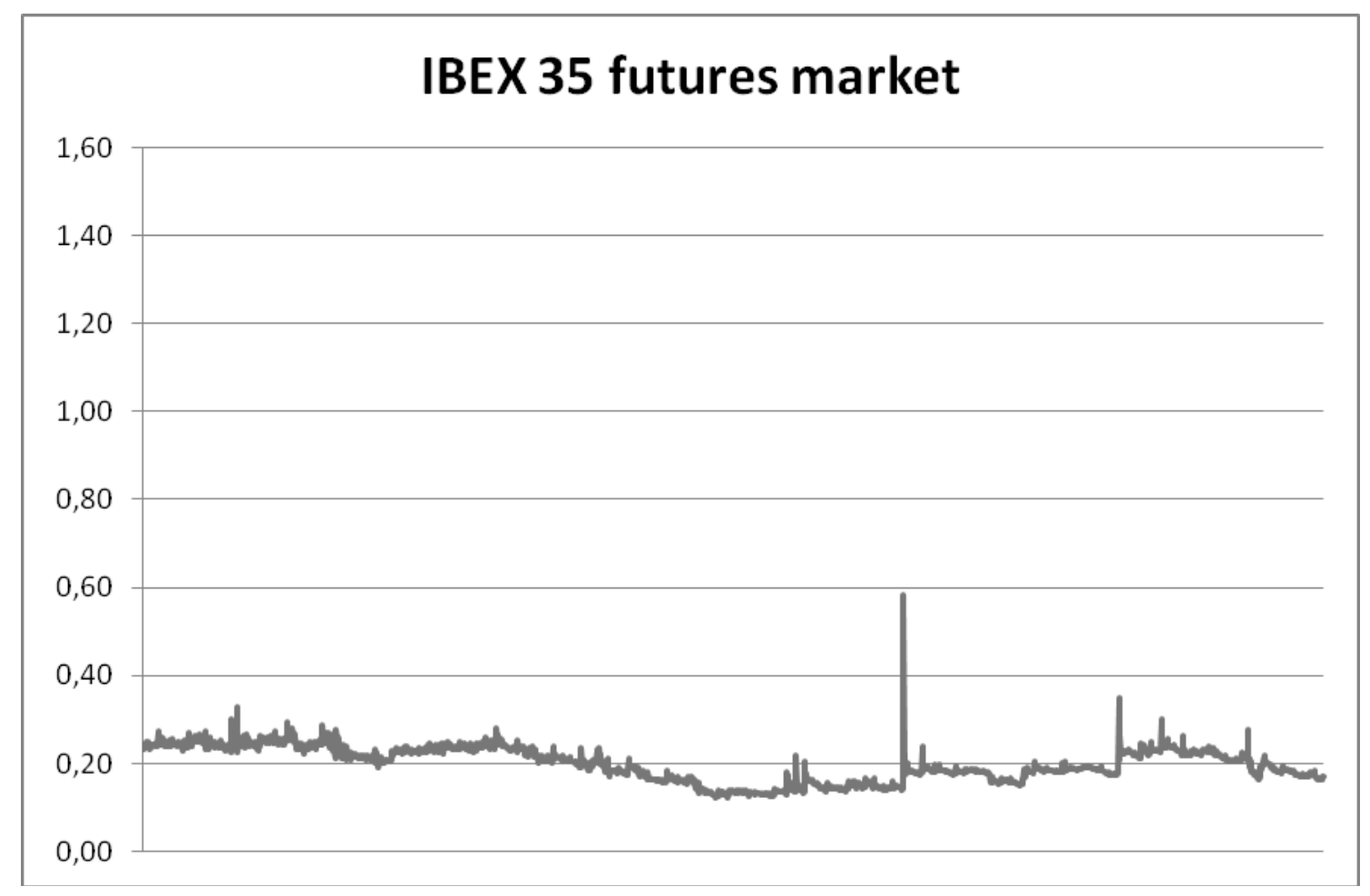

Figure 2c. Ratio of estimated variances for specific and common noise components: Ibex35. 